\title{
DESENVOLVIMENTO E TEOR DE PROTEÍNA EM ORA-PRO-NÓBIS INFLUENCIADOS POR DIFERENTES CONDIÇÕES DE LUMINOSIDADE
}

\author{
Joel Soares Vieira ${ }^{1}$, Clarice Aparecida Megguer², Ubiramar Ribeiro Cavalcante ${ }^{3}$, Flávia Dionizio Pereira ${ }^{4}$, \\ Muriel Silva Vilarinho 5
}

\begin{abstract}
RESUMO - A ora-pro-nóbis (Pereskia aculeata Miller) é uma planta nativa do Brasil, considerada uma espécie do grupo das plantas alimentícias não convencionais e se destaca por ser rica em substâncias nutritivas e antioxidantes. Ocorre no Brasil em florestas, em meio a clareiras, o que leva a crer que a luz é um fator que influencia o seu desenvolvimento. Acredita-se que em condições artificiais de luz sua produção possa ser aumentada, considerando que alterações na qualidade espectral da luz podem proporcionar mudanças fisiológicas positivas nas plantas. O uso de telas fotosseletivas, visa combinar a proteção física das plantas, com a filtragem seletiva da radiação solar para promover respostas fisiológicas desejáveis, reguladas pela luz. Não foi encontrada literatura associando o uso de telas ao cultivo de ora-pro-nóbis. Neste contexto, objetivouse avaliar o desenvolvimento e teor de proteína de plantas de ora-pro-nóbis cultivadas sob telas fotosseletivas e a pleno sol. O experimento foi conduzido em delineamento de blocos casualizados (DBC), com parcelas subdivididas no tempo, com quatro repetições. As parcelas foram compostas por quatro ambientes (telas ChromatiNet ${ }^{\circledR}$ Leno Azul, ChromatiNet ${ }^{\circledR}$ Leno Pérola, ChromatiNet ${ }^{\circledR}$ Leno Vermelha, todas com $20 \%$ de sombreamento e a pleno sol) e as subparcelas constituídas de duas épocas de amostragens, aos 80 e 120 dias após o transplantio (DAT) das mudas. Os parâmetros avaliados foram: teor de proteína das folhas, número de folhas, diâmetro do colo da planta, massa da matéria fresca e seca da folha, caule e raiz. Na amostragem aos 120 DAT, as plantas cultivadas sob tela pérola obtiveram os melhores resultados para massa da matéria fresca da folha, massa da matéria seca da folha e caule, diâmetro do colo da planta e número de folhas. O ambiente de cultivo proporcionou alterações no desenvolvimento e teor de proteína de ora-pro-nóbis.
\end{abstract}

Palavras-chave: fotomorfogênese, fotorreceptores, Pereskia aculeata Miller, planta alimentícia não convencional.

\section{DEVELOPMENT AND PROTEIN CONTENT IN ORA-PRO-NOBIS INFLUENCED BY DIFFERENT LIGHT CONDITIONS}

\begin{abstract}
The ora-pro-nóbis (Pereskia aculeata Miller) is a native plant of Brazil, considered a species of the group of unconventional food plants and stands out for being rich in nutrients and antioxidants. The use of photoselective screens aims to combine the physical protection of plants with the selective filtering of solar radiation to promote desirable physiological responses, regulated by light. Occurs in Brazil in forests, among clearings, which leads to believe that light is a factor that influences its development. It is believed
\end{abstract}

\footnotetext{
${ }^{1}$ Professor, MSc., Universidade Aberta Integrada - UAITEC e Escola Municipal Manoel Alves Vilela, Ituiutaba, MG, Brasil, josovi41@ yahoo.com.br;

2 Professora, Doutora, Instituto Federal de Educação, Ciência e Tecnologia Goiano-IFGoiano, Morrinhos, GO, Brasil, clarice.megguer@ ifgoiano.edu.br;

${ }^{3}$ Professor, MSc. Universidade do Estado de Minas Gerais-UEMG, Ituiutaba, MG, Brasil, ubiramarrc@gmail.com;

${ }^{4}$ Professora, Doutora, Instituto Federal de Educação, Ciência e Tecnologia Goiano-IFGoiano, Morrinhos, GO, Brasil, flavia1808@, hotmail.com;

${ }^{5}$ Professora, MSc., Universidade do Estado de Minas Gerais-UEMG, Ituiutaba, MG, Brasil, murielvilarinho@hotmail.com.
} 


\begin{abstract}
that under artificial light conditions its production may be increased, considering that changes in the spectral quality of light may provide positive physiological changes in plants. No literature was found associating the use of screens with ora-pro-nobis cultivation. In this context, the objective was to evaluate the development and protein content of ora-pro-nobis cultivated plants under photoselective screens and in full sun. The experiment was conducted in a randomized block design (DBC), with time subdivided plots, with four replications. The plots were composed of four environments (ChromatiNet ${ }^{\circledR}$ Leno Blue, ChromatiNet ${ }^{\circledR}$ Leno Pearl, ChromatiNet $\AA$ Leno red screens, all with $20 \%$ shading and full sun) and the subplots consisting of two sampling periods, at 80 and 120 days after transplantation (DAT) of seedlings. The evaluated parameters were: leaf protein content, leaf number, plant diameter, leaf fresh and dry matter mass, stem and root. In the 120 DAT sampling, plants cultivated under pearl screen obtained the best results for leaf fresh matter mass, leaf and stem dry matter mass, plant diameter and leaf number. The culture environment provided alterations in the development and protein content of ora-pro-nóbis.
\end{abstract}

Keywords: photomorphogenis, photoreceptors, Pereskia aculeata Miller, unconventional food plants.

\section{INTRODUÇÃO}

A ora-pro-nóbis (Pereskia aculeata Miller) é uma planta nativa do Brasil, mas não endêmica, podendo ser encontrada desde a Argentina até a Flórida (Madeira et al., 2013). No Brasil, é encontrada nas regiões Nordeste nos estados de Alagoas, Bahia, Ceará, Maranhão, Pernambuco e Sergipe, Centro-Oeste em Goiás, Sudeste no Espírito Santo, Minas Gerais, Rio de Janeiro e São Paulo e na região Sul do país nos estados do Paraná, Rio Grande do Sul e Santa Catarina (Zappi et al., 2010). Possuem hábito escandente, que tende a apoiar-se em outra planta, no caso das florestas, em árvores. Ocorrem preferencialmente nas orlas e nas clareiras de florestas (Engel et al., 1998; Souza, 2013).

É uma espécie considerada do grupo das plantas alimentícias não convencionais (PANC) e se destaca por ser rica em substâncias nutritivas e antioxidantes (Queiroz et al., 2015). Recomenda-se que a colheita do ora-pro-nóbis (OPN) seja iniciada de 2 a 3 meses após o seu plantio, quando as folhas apresentam em média 7 a $10 \mathrm{~cm}$ de comprimento (Brasil, 2016). As folhas de OPN possuem na base seca $39,1 \%$ de fibra dietética total, $17,4 \%$ de proteína total (Almeida Filho; Cambraia, 1974) a $28,4 \%, 3,42 \mathrm{mg} 100 \mathrm{~g}^{-1}$ de cálcio, $1,9 \mathrm{mg}$ $100 \mathrm{~g}^{-1}$ de magnésio, $46,4 \mathrm{mg} 100 \mathrm{~g}^{-1}$ de manganês, $26,7 \mathrm{mg}$ $100 \mathrm{~g}^{-1}$ de zinco e $2333 \mathrm{UI} 100 \mathrm{~g}^{-1}$ de vitaminas A, 185,8 mg $100 \mathrm{~g}^{-1}$ de vitamina C e 19,3 mg $100 \mathrm{~g}^{-1}$ de ácido fólico. Possui ainda $5,52 \%$ de triptofano, que equivale a $20,5 \%$ do total dos aminoácidos presentes nas folhas (Takeiti et al., 2009). Devido a esses teores nutricionais observa-se o crescente interesse pelo uso de OPN como matéria-prima pela indústria alimentícia na forma desidratado e moído (farinha das folhas), e do consumo direto como hortaliça folhosa pela população. Diante dessa perspectiva é importante buscar tecnologias para aumentar a produtividade e manejo da cultura. As telas fotosseletivas tem sido utilizadas no cultivo de diferentes espécies vegetais como fator de proteção, principalmente aos extremos de temperatura (Neto et al., 2010) e condições climáticas adversas (Ángel-hernández et al., 2017) ou para a modificação do espectro luminoso que incide nas plantas. As plantas têm habilidade para modificar o seu modelo de desenvolvimento em resposta ao ambiente luminoso. As respostas de crescimento e desenvolvimento se devem à modificação da luz solar em luz difusa, seleção de diferentes comprimentos de onda e reflexão da radiação térmica, devido à incorporação de aditivos cromáticos e elementos dispersivos às telas fotosseletivas (Corrêa et al., 2012).

Entretanto, sabe-se que fatores climáticos, endógenos, bióticos, abióticos e até fatores técnicos, como forma de plantio, escolha de substratos (Cavalcante et al., 2019) e cultivo, influenciam no desenvolvimento das plantas e na produção de princípios ativos. Por essa razão, é importante associar às características de desenvolvimento e crescimento das plantas de OPN, de forma que seja possível indicar formas de manejo agronômico que possam maximizar sua produção de acordo com os interesses de uso (Queiroz et al., 2015). Alterações na qualidade espectral da luz podem proporcionar mudanças fisiológicas e aumento da produção. Não encontrou-se literatura associando o uso de telas ao cultivo de OPN.

Neste contexto, objetivou-se com esse estudo avaliar o desenvolvimento e teor de proteína de plantas de OPN cultivadas, sob telas fotosseletivas e a pleno sol.

\section{MATERIAL E MÉTODOS}

O experimento foi conduzido em Ituiutaba, Minas Gerais, Brasil, no período de dezembro de 2016 a abril de 2017, estando o município localizado a $18^{\circ} 57^{\prime} 03^{\prime \prime}$ $\mathrm{S}, 49^{\circ} 31$ '31" W e altitude de $530 \mathrm{~m}$, o clima da região é 
classificado como AW quente úmido segundo a classificação de Köppen-Geiger.

O solo da área de plantio foi classificado como Latossolo Vermelho Eutroférrico (Embrapa, 1999). A análise química do solo apresentou as seguintes características na camada arável de $0-20 \mathrm{~cm}: \mathrm{pH}$ em $\mathrm{CaCl}_{2}$ de 4,7;16,6 $\mathrm{g} \mathrm{dm}^{-3}$ de matéria orgânica; $\mathrm{V}$ de 40,91\%; 1,2 $\mathrm{cmol} \mathrm{dm}^{-3}$ de Ca; 0,8 $\mathrm{cmol} \mathrm{dm}^{-3}$ de $\mathrm{Mg} ; 3,3 \mathrm{cmol} \mathrm{dm}^{-3}$ de $\mathrm{H}+\stackrel{\mathrm{c}}{\mathrm{A}} ; 10,3 \mathrm{mg} \mathrm{dm}^{-3}$ de P; e $0,111,0,6,12,3,32,8,1,7 \mathrm{e}$ $0,05 \mathrm{mg} \mathrm{dm}^{-3}$ de K, Zn, Fe, Mn, Cu e B, respectivamente. A classe textural do solo é argilosa, com 298, 345 e $357 \mathrm{~g} \mathrm{dm}^{-3}$ de areia, silte e argila, respectivamente.

Para a produção das mudas de OPN foi utilizada a propagação vegetativa de plantas matrizes cultivadas na cidade de Ituiutaba-MG, sendo que exsicatas da espécie estão depositadas no Herbarium Uberlandense (HUFU) da Universidade Federal de Uberlândia (UFU), sob o registro número HUFU 22511. As estacas foram retiradas da porção basal dos ramos que brotaram no mesmo ano, sendo realizado o desbaste das folhas e das ramificações laterais, permanecendo os acúleos, em seguida, foram padronizadas com $20 \mathrm{~cm}$ de comprimento. As estacas foram plantadas em sacos de polietileno preto de $10 \mathrm{~cm}$ de largura, $15 \mathrm{~cm}$ de comprimento e $0,10 \mathrm{~cm}$ de espessura, onde foram inseridas a uma profundidade de $5 \mathrm{~cm}$. O substrato utilizado foi composto de solo + areia lavada + esterco bovino curtido (2:1:1), preparado por meio de homogeneização manual (Cavalcante et al., 2019). As mudas foram dispostas sob tela preta, com $50 \%$ de sombreamento, até o ponto de plantio.

O transplantio para a área experimental foi realizado quando as mudas completaram 40 dias. $\mathrm{O}$ experimento foi conduzido em delineamento de blocos casualizados (DBC), com parcelas subdivididas no tempo, com quatro repetições. As parcelas foram compostas por quatro ambientes (telas ChromatiNet ${ }^{\circledR}$ Leno Azul, ChromatiNet ${ }^{\circledR}$ Leno Pérola, ChromatiNet ${ }^{\circledR}$ Leno Vermelha, todas com $20 \%$ de sombreamento e a pleno sol) e as subparcelas constituídas de duas épocas de amostragens, aos 80 e 120 dias após o transplantio (DAT) das mudas. Os telados foram construídos em estruturas de madeira de $5,00 \times 4,00 \times 1,70 \mathrm{~m}$ (comprimento, largura e altura), com um esteio central de $2,00 \mathrm{~m}$. Cada estrutura de madeira foi coberta individualmente, no teto e nas laterais, com as respectivas telas de sombreamento.

Para correção do solo utilizou-se calcário dolomítico, com PRNT de $92 \%$ e a adubação de plantio seguiu a recomendação para o cultivo da roseira, já que não há trabalhos indicando adubação para o OPN (Madeira et al., 2013) conforme as "Recomendações para o uso de corretivos e fertilizantes em Minas Gerais" (Ribeiro et al., 1999). Assim, para adubação no plantio utilizou-se $200 \mathrm{~g}$ de húmus de minhocas, $250 \mathrm{~g}$ de 4 - 14 - 8 por cova, com base na análise de solo. A irrigação foi realizada uma vez por dia, manualmente, com regador de crivo fino, na quantidade de $2 \mathrm{~L} \mathrm{~m}^{-2}$. Aos 60 DAT foi feita adubação de cobertura com sulfato de amônia na dosagem de $40 \mathrm{~kg} \mathrm{ha}^{-1}$.

Adotou-se o espaçamento de 1,0 m entre linhas de plantio e 0,50 m entre plantas (Brasil, 2010), perfazendo um total de 20 plantas por cada parcela experimental. A parcela útil constituiu-se por quatro plantas, sendo duas plantas por cada avaliação. Nas duas avaliações foram analisados os parâmetros: número de folhas, determinado por contagem simples; diâmetro do colo da planta, obtido com um paquímetro analógico, aferindo-se a região do colo, sendo os resultados expressos em milímetros. Para avaliar a produção foi determinada a massa da matéria fresca e seca de todo material colhido, as plantas foram separadas em raízes, caules (caule principal + ramos) e folhas. $\mathrm{Na}$ determinação da massa da matéria fresca foi pesado cada parte da planta separadamente em balança digital. Em seguida, o material vegetal fresco foi acondicionado em sacos de papel, identificados e levados para secar a $70{ }^{\circ} \mathrm{C}$ em estufa com circulação forçada de ar por 72 horas, momento em que atingiu estabilidade da matéria seca, sendo os resultados expressos em gramas. Para a análise do teor de proteína bruta foram coletadas oito folhas por parcela e imediatamente acondicionadas em sacos de papel, encaminhadas ao laboratório, onde a quantificação de proteínas totais das amostras foram realizadas de acordo com a metodologia (Galvani \& Gaertner, 2006), com modificações. Pesou-se aproximadamente $0,2 \mathrm{~g}$ da amostra vegetal in natura que foi levada para digestão por aproximadamente 10 horas. Seguiu-se a destilação do nitrogênio e posterior titulação com $\mathrm{HCl}$. O teor de proteína foi calculado utilizando o fator de conversão para vegetais 5,75. Os resultados foram expressos como média de duplicatas, seguidas de desvio padrão.

Os dados obtidos no experimento foram submetidos à análise de variância, e as médias comparadas pelo teste de Scott-Knott $(p<0,05)$, utilizando-se do software SISVAR (Ferreira, 2011).

\section{RESULTADOS E DISCUSSÃO}

Houve aumento significativo da massa da matéria fresca da folha do OPN sob a tela pérola, na amostragem aos 120 DAT, em relação ao demais tratamentos (Tabela 1). Esse resultado pode ser atribuído ao efeito da eficiência fotossintética, proporcionada pela maior quantidade de luz difusa sob a tela pérola, quando comparada aos tratamentos com telas vermelha, azul e a pleno sol. Shahak et al. (2004) 
verificaram que a tela pérola melhora a penetração da luz no dossel das plantas, pois propicia maior difusão de luz $(62 \%)$, contra $(35,6 \%)$ da tela vermelha e $(26,0 \%)$ da tela azul. Em seu trabalho com cultivo de alface de verão cultivar Tizian Ilić et al. (2017) obtiveram maior peso da cabeça, sob a tela pérola e vermelha.

Tabela 1 - Massa da matéria fresca da folha, do caule e da raiz de ora-pro-nóbis, cultivadas sob telas fotosseletivas com $20 \%$ de sombreamento e a pleno sol, aos 80 e 120 dias após o transplantio (DAT)

\begin{tabular}{|c|c|c|c|c|}
\hline \multirow{3}{*}{ DAT } & \multicolumn{4}{|c|}{ Massa da matéria fresca $(\mathrm{g})$} \\
\hline & Tela azul & Tela pérola & Tela vermelha & Pleno sol \\
\hline & \multicolumn{4}{|c|}{ Folha } \\
\hline 80 & $340,5 \pm 178,6 \mathrm{Ba}$ & $353,6 \pm 114,2 \mathrm{Ba}$ & $298,8 \pm 72,4 \mathrm{Ba}$ & $329,2 \pm 107,8 \mathrm{~B}$ \\
\hline \multirow[t]{2}{*}{120} & $667,2 \pm 147,3 \mathrm{Ab}$ & $1119,7 \pm 303,5 \mathrm{Aa}$ & $765,4 \pm 122,6 \mathrm{Ab}$ & $817,4 \pm 206,8 \mathrm{Ab}$ \\
\hline & \multicolumn{4}{|c|}{ Caule } \\
\hline 80 & $191,1 \pm 146,4 \mathrm{Ba}$ & $167,5 \pm 77,5 \mathrm{Ba}$ & $137,2 \pm 51,3 \mathrm{Ba}$ & $132,4 \pm 57,5 \mathrm{Ba}$ \\
\hline \multirow[t]{2}{*}{120} & $689,3 \pm 471,6 \mathrm{Aa}$ & $992,9 \pm 248,5 \mathrm{Aa}$ & $575,0 \pm 146,4 \mathrm{Aa}$ & $713,4 \pm 247,1 \mathrm{Aa}$ \\
\hline & \multicolumn{4}{|c|}{ Raiz } \\
\hline 80 & $38,8 \pm 24,4 \mathrm{Aa}$ & $27,6 \pm 12,1 \mathrm{Ba}$ & $31,5 \pm 14,9 \mathrm{Ba}$ & $24,1 \pm 12,2 \mathrm{Ba}$ \\
\hline 120 & $46,4 \pm 6,5 \mathrm{Ab}$ & $80,0 \pm 21,4 \mathrm{Aa}$ & $64,9 \pm 17,2 \mathrm{Aa}$ & $70,1 \pm 15,3 \mathrm{Aa}$ \\
\hline
\end{tabular}

Médias seguidas de letras maiúsculas iguais nas colunas, e minúsculas nas linhas, não diferem significativamente entre si pelo teste de Scott-Knott ao nível de 5\% de probabilidade.

Para a massa da matéria fresca da folha, do caule e da raiz, na interação entre os tratamentos e o tempo de amostragem, verificou-se que aos 120 DAT, todos os tratamentos apresentaram significância quando comparados à amostragem aos 80 DAT, com exceção da tela azul, que não diferiu para a massa da matéria fresca de raiz (Tabela 1). Esses resultados demonstram que, em plantios comerciais, com o objetivo de produção de folhas para consumo in natura ou da farinha das folhas desidratadas, é interessante retardar a colheita inicial, buscando maior produtividade e estabelecimento da cultura. Recomenda-se (Brasil, 2016) que a colheita do OPN seja iniciada de 2 a 3 meses após o seu plantio, quando as folhas apresentam em média 7 a 10 cm de comprimento.

Plantas de OPN cultivadas sob tela pérola e vermelha, obtiveram maiores ganhos de massa da matéria seca da folha na amostragem aos 120 DAT, que aquelas cultivadas a pleno sol e sob a tela azul (Tabela 2). Estudos de Souza et al. (2014) apontam que, sob tela vermelha, várias espécies apresentam maiores taxas de crescimento devido à mudança espectral (maior transmitância de comprimentos de ondas no vermelho e vermelho - distante) e aumento na percentagem de luz difusa. Plantas heliófitas como o OPN, utilizam com eficiência altas intensidades de radiação, graças à elevada capacidade do transporte de elétrons, conseguindo maiores ganhos fotossintéticos
(Larcher, 2004). A redução de $20 \%$ na intensidade luminosa, promovida pelas telas pérola e vermelha, não comprometeram a eficiência fotossintética. A mudança no espectro de luz promovido pela tela vermelha e pérola evidencia que as plantas de OPN respondem à qualidade de luz. Em experimento com agrião, sob telas e a pleno sol, não houve diferença entre os tratamentos quanto à massa da matéria seca das folhas e talos, das plantas oriundas de mudas; já para as plantas oriundas da rebrota, com o cultivo sob telas, obteve-se maiores médias em relação ao cultivo a pleno sol (Hirata \& Hirata, 2015).

As plantas cultivadas sob tela pérola obtiveram maior média para a massa da matéria seca do caule na amostragem aos 120 DAT, em relação aos demais tratamentos (Tabela 2). Esse resultado demonstra uma alocação preferencial de fotossintatos para os ramos e caule, e que o sombreamento de $20 \%$ não comprometeu a fotossíntese, compensada pela maior disponibilidade de luz difusa. Em condições de diferentes luminosidades, Queiroz et al. (2015) observou que na condição totalmente sombreada, a produção de massa da matéria seca de caules e folhas de OPN foi de 3,2\% e 9,7\% da massa média, obtida nos tratamentos na condição sem sombreamento e à meia sombra $\left(9,3 \pm 2,4\right.$ e 5,2 $\pm 1,1 \mathrm{~g}$ planta $\left.^{-1}\right)$, respectivamente. De acordo com Gama et al. (2017) em experimento com diferentes cultivares de mini-tomates e tempos de 
amostragem sob telas de sombreamento vermelha, azul, cinza e a pleno sol, verificaram que houve acréscimo de massa da matéria seca nos diferentes órgãos das plantas para todos os tipos de ambiente e que o maior acúmulo ocorreu no ambiente com tela vermelha.

Tabela 2 - Massa da matéria seca de folha, caule e raiz de ora-pro-nóbis, cultivadas sob telas fotosseletivas com $20 \%$ de sombreamento e a pleno sol, aos 80 e 120 dias após o transplantio (DAT)

\begin{tabular}{ccccc}
\hline \multicolumn{5}{c}{ Massa da matéria seca $(\mathrm{g})$} \\
\hline \multirow{2}{*}{ DAT } & Tela azul & Tela pérola & Tela vermelha & Pleno sol \\
\cline { 2 - 5 } 80 & & & Folha & \\
120 & $37,3 \pm 21,2 \mathrm{Aa}$ & $43,7 \pm 18,9 \mathrm{Ba}$ & $40,1 \pm 23,2 \mathrm{Ba}$ & $41,9 \pm 24,9 \mathrm{Aa}$ \\
$82,6 \pm 12,3 \mathrm{Ab}$ & $108,2 \pm 14,9 \mathrm{Aa}$ & $102,6 \pm 69,3 \mathrm{Aa}$ & $73,3 \pm 11,3 \mathrm{Ab}$ \\
\hline & & Caule & \\
120 & $45,0 \pm 35,4 \mathrm{Ba}$ & $37,5 \pm 18,3 \mathrm{Ba}$ & $31,2 \pm 12,6 \mathrm{Ba}$ & $31,6 \pm 15,9 \mathrm{Ba}$ \\
80 & $176,0 \pm 90,0 \mathrm{Ab}$ & $265,5 \pm 43,0 \mathrm{Aa}$ & $175,6 \pm 54,9 \mathrm{Ab}$ & $138,5 \pm 25,9 \mathrm{Ab}$ \\
\hline & & Raiz & \\
120 & $9,5 \pm 7,6 \mathrm{Aa}$ & $8,1 \pm 2,7 \mathrm{Ba}$ & $9,5 \pm 4,0 \mathrm{Ba}$ & $6,6 \pm 3,4 \mathrm{Ba}$ \\
\hline
\end{tabular}

Médias seguidas de letras maiúsculas iguais nas colunas, e minúsculas nas linhas, não diferem significativamente entre si pelo teste de Scott-Knott ao nível de $5 \%$ de probabilidade.

$\mathrm{Na}$ interação telas e tempo de amostragem para o número de folhas, todos os tratamentos apresentaram significância na colheita aos 120 DAT em relação aos 80 DAT (Tabela 3). Não houve significância entre os tratamentos para o número de folhas aos 80 DAT, sendo que na amostragem aos 120 DAT sob tela pérola foi superior (Tabela 3). Sugere-se que esse maior número de folhas das plantas ocorra devido à maior radiação fotossintéticamente ativa e a luz difusa proporcionada pela tela pérola. No cultivo de alecrim a pleno sol e sob telados vermelho e azul, aos 120 dias, a tela azul apresentou maior número de folhas
(Souza et al. 2014). Cultivando mudas de cafeeiro sob telas Henrique et al. (2011) não obteve diferença significativa para o número de folhas entre os tratamentos (tela azul, branca, cinza, preta e vermelha). Utilizando-se de telas como subcobertura em estufa no cultivo hidropônico de alface Sales et al. (2014) observaram que no ambiente que apresentou menor acúmulo térmico, obteve maior número de folhas medindo mais que $10 \mathrm{~cm}$ (tela termorrefletora e preta), e os ambientes com maior acúmulo térmico (sem tela e tela vermelha), apresentaram um menor número de folhas medindo mais que $10 \mathrm{~cm}$.

Tabela 3 - Diâmetro do colo da estaca, número de folhas e teor de proteína das folhas frescas de ora-pro-nóbis, cultivadas sob telas fotosseletivas com $20 \%$ de sombreamento e a pleno sol, aos 80 e 120 dias após o transplantio (DAT)

\begin{tabular}{|c|c|c|c|c|}
\hline \multirow{2}{*}{ DAT } & Tela azul & Tela pérola & Tela vermelha & Pleno sol \\
\hline & \multicolumn{4}{|c|}{ Diâmetro do colo $(\mathrm{mm})$} \\
\hline 80 & $9,0 \pm 1,5 \mathrm{Ba}$ & $9,5 \pm 2,2 \mathrm{Ba}$ & $8,2 \pm 0,5 \mathrm{Ba}$ & $6,9 \pm 1,1 \mathrm{Ba}$ \\
\hline \multirow[t]{2}{*}{120} & $21,0 \pm 3,0 \mathrm{Ab}$ & $26,5 \pm 1,9 \mathrm{Aa}$ & $20,2 \pm 1,4 \mathrm{Ab}$ & $21,1 \pm 0,9 \mathrm{Ab}$ \\
\hline & \multicolumn{4}{|c|}{ Número de folhas } \\
\hline 80 & $332,1 \pm 81,1 \mathrm{Ba}$ & $273,0 \pm 86,4 \mathrm{Ba}$ & $222,8 \pm 26,9 \mathrm{Ba}$ & $243,4 \pm 28,9 \mathrm{Ba}$ \\
\hline \multirow[t]{2}{*}{120} & $532,8 \pm 215,5 \mathrm{Ab}$ & $720,5 \pm 108,3 \mathrm{Aa}$ & $496,8 \pm 140,5 \mathrm{Ab}$ & $542,5 \pm 103,4 \mathrm{Ab}$ \\
\hline & \multicolumn{4}{|c|}{ Proteína $(\%)$} \\
\hline 80 & $3,3 \pm 0,1 \mathrm{Aa}$ & $3,0 \pm 0,5 \mathrm{Aa}$ & $2,4 \pm 0,6 \mathrm{Bb}$ & $2,9 \pm 0,6 \mathrm{Ba}$ \\
\hline 120 & $3,4 \pm 0,2 \mathrm{Aa}$ & $3,4 \pm 0,3 \mathrm{Aa}$ & $3,4 \pm 0,7 \mathrm{Aa}$ & $3,6 \pm 0,5 \mathrm{Aa}$ \\
\hline
\end{tabular}

Médias seguidas de letras maiúsculas iguais nas colunas, e minúsculas nas linhas, não diferem significativamente entre si pelo teste de Scott-Knott ao nível de $5 \%$ de probabilidade. 
Na interação tratamento e tempo de amostragem, a diferença do teor de proteína nas folhas frescas de OPN foi significativa, sendo que as plantas a pleno sol e sob telado vermelho aos 120 DAT obtiveram as maiores médias em relação aos 80 DAT. Não houve significância entre os tratamentos aos 120 DAT, para o teor de proteína, já aos 80 DAT a tela vermelha obteve a menor média, diferindo dos demais tratamentos (Tabela 3). Esses resultados demonstram que plantas de OPN ajustam seu metabolismo na produção de proteinas em função da qualidade e intensidade luminosa. Estudando a influência da intensidade de luz através de diodos emissores de luz (LED's) azul, verde e vermelha em plantas de alface Muneer et al. (2014) verificaram que diferentes intensidades de luz interferem na expressão das proteínas nos tilacóides e que a luz azul com alta intensidade, controlou a integridade das proteínas do cloroplasto elevando o desempenho fotossintético. As plantas sob LED's verdes e vermelhos com baixa intensidade de luz tiveram redução dos complexos de proteínas dos tilacóides, indicando uma dependência próxima do metabolismo fotossintético com intensidade e fonte de luz. No cultivo de OPN em ambientes sem sombreamento, meia sombra (sombrite $50 \%$ ) e totalmente sombreado Queiroz et al. (2015) verificaram que o teor de proteínas nas folhas em condição sombreada foi $74 \%$ superior em relação ao ambiente meia sombra e, em cerca de $68 \%$ em plantas sem sombreamento, evidenciando que essas plantas apresentam modificações metabólicas para ajuste e manutenção do desenvolvimento em função das condições de intensidade luminosa

Para o diâmetro do colo da planta houve interação significativa entre os tratamentos e tempo de amostragem, sendo as maiores médias obtidas aos 120 DAT em relação aos 80 DAT (Tabela 3). Considerando os tratamentos na amostragem aos 80 DAT, não houve interação significativa, sendo que o maior diâmetro do colo foi obtido no cultivo sob tela pérola aos 120 DAT (Tabela 3). Esse resultado é corroborado por Queiroz et al. (2015), em seu trabalho com diferentes luminosidades em OPN, o maior diâmetro do colo de plantas foi alcançado em condição sem sombreamento e meia sombra, sendo superiores ao tratamento totalmente sombreado. A redução da radiação solar promovida pelas telas utilizadas nesse trabalho, não comprometeram a produção de OPN.

\section{CONCLUSÕES}

A mudança espectral promovida pelas telas no ambiente de cultivo afeta o desenvolvimento e o teor de proteína de OPN. Entre os quatro ambientes estudados, o uso da tela pérola é a mais recomendada no cultivo de OPN e colheita aos 120 DAT, pois proporciona maior produção de massa da matéria fresca e seca de folha e caule, diâmetro do colo da planta e número de folhas de OPN. A redução de $20 \%$ na radiação solar, promovida pelas telas, não afeta o desenvolvimento das plantas de OPN.

\section{LITERATURA CITADA}

ALMEIDA FILHO, J.; CAMBRAIA, J. Estudo do valor nutritivo do ora-pro-nobis (Pereskia aculeata Mill.). Revista Ceres, v.21, n.114, p.105-111, 1974.

ÁNGEL-HERNÁNDEZ, M.D.; ALEJANDRO ZERMEÑO-GONZALEZ, A.; MELENDRES-ALVAREZ, A.I. et al. Características de la cubierta de un túnel efecto en radiación, clorofila y rendimiento de calabacita. Revista Mexicana de Ciencias Agrícolas, v. 8, n. 5, p. 1127-1142, 2017.

BRASIL. Ministério da Agricultura, Pecuária e Abastecimento. Manual de hortaliças não-convencionais. Secretaria de Desenvolvimento Agropecuário e Cooperativismo. Brasília: Mapa/ACS, 2010. 92p.

BRASIL. Ministério do Meio Ambiente. Espécies nativas da flora brasileira de valor econômico atual ou potencial: Plantas para o futuro: Região Centro-Oeste. Secretaria de Biodiversidade - Brasília, DF: MMA, 2016. 1160p.

CAVALCANTE, U.R.; MEGGUER, C.A.; VIEIRA, J.S. et al. Influence of different parts of cuttings and substrates on vegetative propagation of Pereskia aculeata Miller. Bioscience Journal, v.35, n.3, p. 691-699, 2019.

CORRÊA, R.M.; PINTO, J.E.B.; REIS É.S. et al. Crescimento de plantas, teor e qualidade de óleo essencial de folhas de orégano sob malhas coloridas. Global Science and Technology, v. 5, n. 1, p.11-22, 2012.

EMBRAPA-Empresa Brasileira de Pesquisa Agropecuária. Centro nacional de pesquisa de solos. Sistema brasileiro de classificação de solos. Rio de Janeiro, 1999. 412p.

ENGEL, V.L.; FONSECA, R.C.B.; OLIVEIRA, R.E. Ecologia de lianas e o manejo de fragmentos florestais. Série Técnica IPEF, v. 12, n. 32, p. 43-64, 1998.

FERREIRA, D.F. Sisvar: Computer statistical analyses system. Ciências e Agrotecnologia, Lavras, v. 35, n. 6, p.1039-1042, 2011.

GALVANI, F.; GAERTNER, E. Adequação da metodologia Kjeldahl para determinação de nitrogênio total e proteína bruta. Corumbá: Embrapa Pantanal, 2006. 9p. 
GAMA, D.R.S.; MESQUITA, A.C.; YURI, J.E. et al. Different shading environments impact growth and yield of three mini-tomato cultivars. Revista Caatinga, v. 30, n. 2, p. 324-334, 2017.

HENRIQUE, P.C.; ALVES, J.D.; DEUNER, S. et al. Aspectos fisiológicos do desenvolvimento de mudas de café cultivadas sob telas de diferentes colorações. Pesquisa Agropecuária Brasileira, v. 46, n. 5, p.458-465, 2011.

HIRATA, A.C.S.; HIRATA, E.K. Desempenho produtivo do agrião d'água cultivado em solo sob telas de sombreamento. Pesquisa Agropecuária Brasileira, v. 50, n. 10, p. 895-901, 2015.

ILIĆ, S.Z.; MILENKOVIĆ, L.; DIMITRIJEVIĆ, A. et al. Light modification by color quality of lettuce from summer production. Scientia Horticulturae, v. 226, p. 389-397, 2017.

LARCHER, W. Ecofisiologia vegetal. São Carlos: RiMa, 2004. 531p.

MADEIRA, N.R.; SILVA, P.C.; BOTREL, N. et al. Manual de produção de Hortaliças Tradicionais. Brasília, DF: Embrapa, 2013. 155p.

MUNEER, S.; KIM, E.J.; PARK, J.S. et al. Influence of green, red and blue light emitting diodes on multiprotein complex proteins and photosynthetic activity under different light intensities in Lettuce Leaves (Lactuca sativa L.). Internacional Journal of Molecular Scienses, v.15, n. 3, p. 4657-4670, 2014.

NETO, O.N.S.; DIAS, N.S.; ATARASSI, R.T. et al. Produção de alface hidropônica e microclima de ambiente protegido sob malhas termo-refletoras. Revista Caatinga, v. 23, n. 4, p. 84-90, 2010.
QUEIROZ, C.R.A.; MORAES, C.M.S.; ANDRADE, R.R. et al. Crescimento inicial e composição química de Pereskia aculeata Miller cultivada em diferentes luminosidades. Revista Agrogeoambiental, v. 7, n. 4, p. 93-104, 2015.

RIBEIRO, A.C.; GUIMARÃES, P.T.G.; VENEGAS, V.H.A. Recomendação para o uso de corretivos $e$ fertilizantes em Minas Gerais: $5^{a}$ Aproximação. Viçosa: Comissão de Fertilidade do Solo do Estado de Minas Gerais, 1999. 359 p.

SALES, F.A.L.; JOSÉ, A.D.B.F.; BARBOSA, J.P.R.A.D. et al. Telas agrícolas como subcobertura no cultivo de alface hidropônica. Ciência Rural, Santa Maria, v. 44, n. 10, p. 1755-1760, 2014.

SHAHAK, Y.; GUSSAKOVSKY, E.E.; GAL, E. et al. Colornets: crop protection and light-quality manipulation in one technology. Acta Horticulturae, v.659, p.143-151, 2004.

SOUZA, G.S.; SILVA, J.S.; OLIVEIRA, U.C. et al. Crescimento Vegetativo e produção de óleo essencial de plantas de alecrim cultivadas sob telas coloridas. Bioscience Journal, v. 30, n. 3, p.232-239, 2014.

SOUZA, M.R.M. Ora-pro-nobis (Pereskia aculeata Mill.) como alternativa promissora para produção de proteina: densidade de plantio e adubação nitrogenada. Tese (Doutorado em Fitotecnia). Viçosa, MG: UFV, 2013. 89p.

TAKEITI, C.Y.; ANTONIO G.C.; MOTTA, E.M.P. et al. Nutritive evaluation of a non-convencional leafy vegetable (Pereskia aculeata Miller). International Journal of Food Science and Technology, v. 60, n.1, p. 148-160, 2009.

ZAPPI, D.; TAYLOR, N.; MACHADO, M. Cactaceae In: Lista de Espécies da Flora do Brasil. Jardim Botânico do Rio de Janeiro, 2010.

Recebido para publicação em 30/03/2019 e aprovado em 24/10/2019. 